\title{
Experimental and numerical studies of shear pin fractures based on linear and bilinear models
}

\author{
Tianbo Peng*, Ning Guo** \\ *State Key Laboratory of Disaster Reduction in Civil Engineering, Tongji University, Shanghai, China, \\ E-mail:ptb@tongji.edu.cn \\ **State Key Laboratory of Disaster Reduction in Civil Engineering, Tongji University, Shanghai, China, \\ E-mail:2290179818@qq.com
}

cross $^{\text {ref }}$ http://dx.doi.org/10.5755/j01.mech.22.4.16159

\section{Introduction}

Seismic isolation devices are usually adopted to reduce structural seismic responses. Because this kind of devices have smaller horizontal stiffness and load capacity, and requirements under normal service conditions are not met. Therefore, shear pins are usually incorporated with seismic isolation devices to resist horizontal load under normal service conditions. In the commonly used isolation bearings, such as friction pendulum bearings, double spherical seismic isolation bearings and cable-sliding friction seismic isolation bearings, shear pins are all installed [1-4]. For these bearings, the same seismic design philosophy is adopted. Namely, shear pins are used to restrict the relative displacement between the superstructure and the substructure under minor earthquakes and the shear pins will be cut off and the bridge structure will be changed into a seismic isolation system under major earthquakes.

Up to now, effects of shear pin fractures have not been considered in bridge seismic design partly for lack of study on shear pin fractures and insufficient understanding of the mechanism of shear pin fractures. E.T. Filipov et al. investigated the seismic performance of typical configurations currently used in the state of Illinois with two kinds of seismic isolation bearings using retainers or shear pins $[5,6]$. J.S. Steelman et al. carried out static bearing experiments to investigate the parameters of low-profile fixed bearing with weak anchors and weak shear pins in longitudinal and transverse directions [7]. J.E. Rodgers et al. conducted a series of shaking table experiments and numerical simulations to study the effects of connection fractures [8]. Xia et al. investigated the seismic behavior of a continuous girder bridge with the effects of shear pin fractures considered [9]. The model adopted was a combination of the initial hysteretic loop of friction pendulum bearing with a linear forcedisplacement curve. A simplified model of the bridge was established with the finite element software ANSYS.

Although some constitutive models for shear pin fractures were established, however, all the parameters of the models were not established beyond doubt. In this paper, shear fracture tests of shear pins were conducted firstly, and then a linear model and a bilinear model were established. Numerical results of seismic responses with the two models were compared at last.

\section{Shear fracture tests of shear pins}

Shear fracture tests of shear pins were carried out to establish constitutive models of shear pins. The test setup consisted of a top plate, an actuator of $500 \mathrm{kN}$ fixed on the reaction wall, a bottom plate fixed on the ground through a connection plate, as shown in Fig. 1.

The material of all the shear pins was Q345, and the yield and ultimate strength of the material were 360 and $525 \mathrm{MPa}$, respectively. Each shear pin in the test was $200 \mathrm{~mm}$ long and a cylinder with a V-shape groove in the middle, as shown in Fig. 2. So the minimum cross section of a shear pin was in the middle, and the section was designed to be cut off in earthquakes. Four kinds of shear pins numbered from A1 to A4 were manufactured and the diameter of the central section $d=10,15,20,30 \mathrm{~mm}$, respectively.

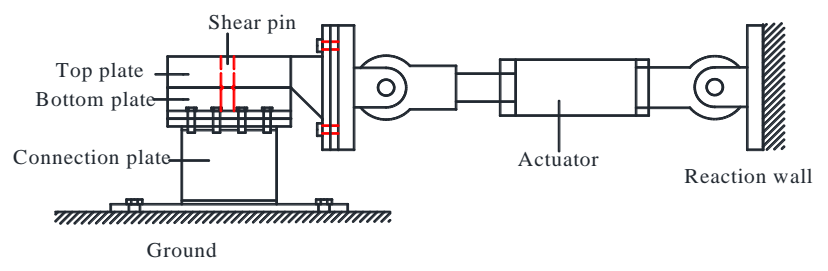

Fig. 1 Setup of shear fracture tests

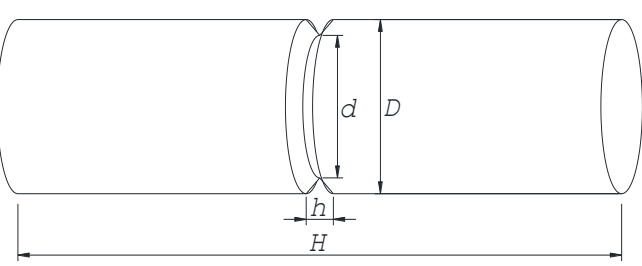

Fig. 2 A shear pin in the test

Before a test, one or two shear pins were inserted in the holes in the top and bottom plates. To simulate the real conditions, a shear fracture tests of shear pins was actually a pure shear test. The two ends of a shear pin were fixed and rotations of shear pins are restricted.

In the test, a displacement transducer was installed between the top and bottom plates and used to measure the relative horizontal displacement between the two plates. Because shear pins were fixed on the plates, the relative horizontal displacement between the two plates was actually the shear deformation of the shear pin. The central sections of shear pins were located at the interface between the top and bottom plates. In the test, the bottom plate was fixed and the top plate was pulled by the actuator. Then the shear pins between the two plates would be cut off. The actuator was controlled with force control load mode. The loading rates were $50 \mathrm{kN} / \mathrm{s}, 250 \mathrm{kN} / \mathrm{s}, 1000 \mathrm{kN} / \mathrm{s}, 1500 \mathrm{kN} / \mathrm{s}, 2000 \mathrm{kN} / \mathrm{s}$, and 
numbered as Rate 1 to 5 respectively. This arrangement was made according to the loading capacity of the actuator.

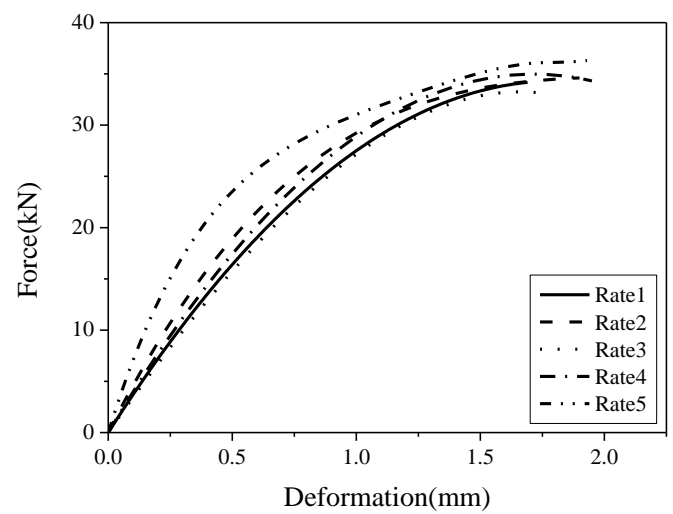

a

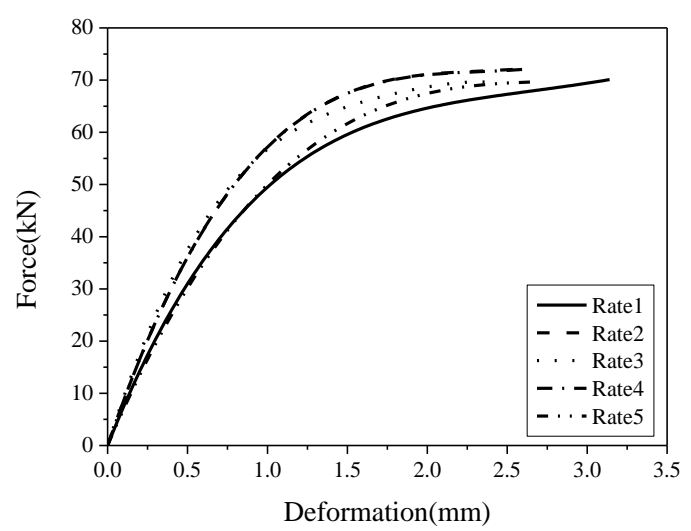

b

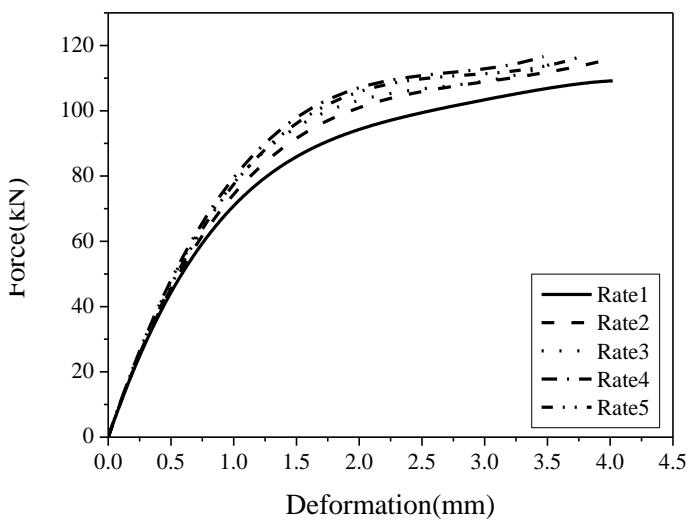

c

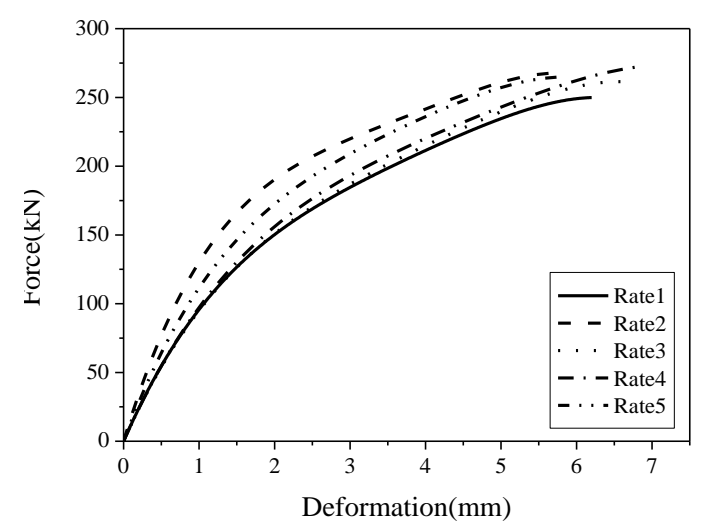

d

Fig. 3 Relations of shear forces to shear deformations: $\mathrm{a}-\mathrm{A} 1 ; \mathrm{b}-\mathrm{A} 2 ; \mathrm{c}-\mathrm{A} 3 ; \mathrm{d}-\mathrm{A} 4$
Relations of shear forces to shear deformations of different shear pins in all the tests are shown in Fig. 3. It's found that each shear pin is cut off when the shear force reaches the maximum value. The maximum shear force during a test is defined as the load capacity $F_{u}$. The deformation corresponding to $F_{u}$ is defined as the ultimate deformation $\Delta_{u}$. Relations of load capacities and ultimate deformations to loading rates are shown in Figs. 4 and 5. As shown, there is a little increase of the load capacity with the increase of the loading rate from Rate 1 to Rate 2 . However, differences in load capacities are small. So, the influence of the loading rate on the load capacity is negligible. It's also found that there are some fluctuations of the ultimate deformation along with the increase of the loading rate, but differences are also small.

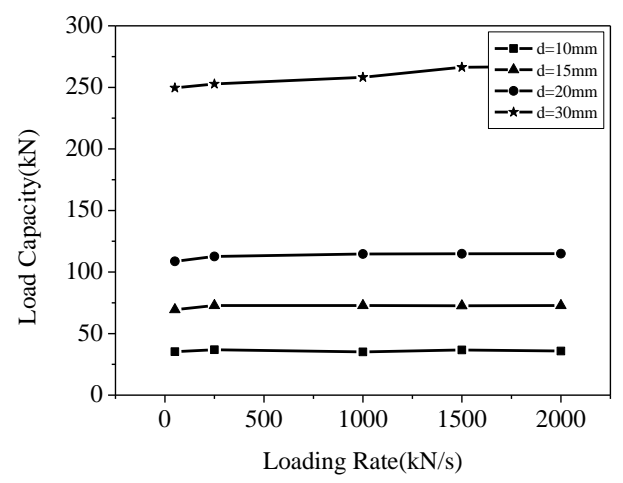

Fig. 4 Relations of load capacities to loading rates

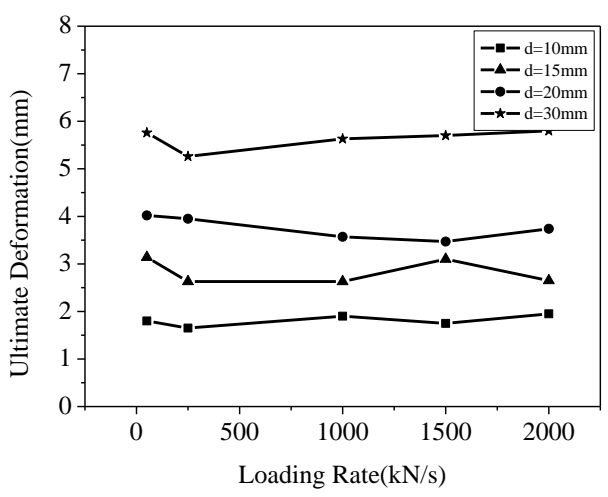

Fig. 5 Relations of ultimate deformations to loading rates

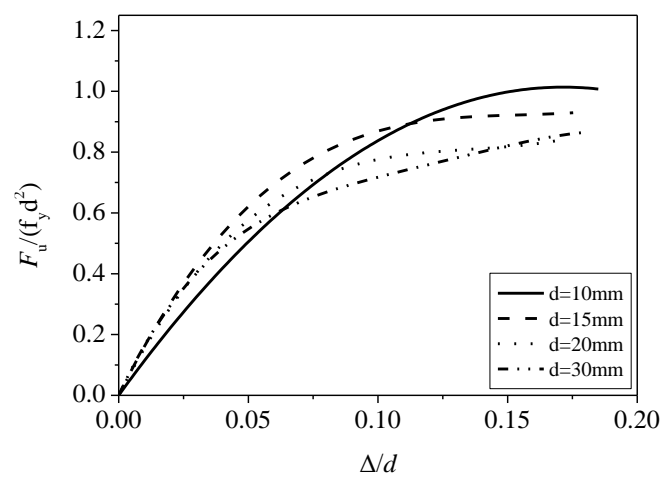

Fig. 6 Relations of dimensionless forces to dimensionless shear deformations

The dimensionless force is defined as $F /\left(f_{y} d^{2}\right)$ and the dimensionless shear deformation is defined as $\Delta / d$. $F$ represents the shear force of the shear pin, $f_{y}$ represents the yield strength of the material and $\Delta$ represents the shear de- 
formation of the shear pin. Relations of dimensionless forces to dimensionless shear deformations are shown in Fig. 6. As shown, maximum dimensionless shear deformations of all the shear pins are almost 0.18 , so the shearing fracture condition of shear pins may be controlled by shear deformations. Maximum dimensionless forces are in the range of 0.81 to 1.02 and decrease with the increase of the shear pin diameter. Relations of dimensionless forces to dimensionless shear deformations are nonlinear, and the dimensionless stiffness decreases with the increase of the dimensionless displacement.

\section{The linear model}

A linear model can be established for shear pin fractures. The model is built according to the origin and the fracture point. There are three parameters in the model: the load capacity $F_{u}$, the ultimate deformation $\Delta_{u}$ and the equivalent stiffness $k_{e q}$. And $k_{e q}$ equals the ratio of $F_{u}$ to $\Delta_{u}$. Relations of $\Delta_{u}$ to $d$ and $F_{u}$ to $d^{2}$ are shown in Fig. 7. As shown, relations of $\Delta_{u}$ to $d$ and $F_{u}$ to $d^{2}$ are almost linear. Empirical formulae for $\Delta_{u}(\mathrm{~mm}), F_{u}(\mathrm{kN}), k_{e q}(\mathrm{kN} / \mathrm{mm})$ and $d(\mathrm{~mm})$ can be fitted by the least square method and described as:

$$
\begin{aligned}
& \Delta_{u}=0.1832 d ; \\
& F_{u}=0.2936 d^{2} ; \\
& k_{e q}=F_{u} / \Delta_{u}=1.6026 d .
\end{aligned}
$$

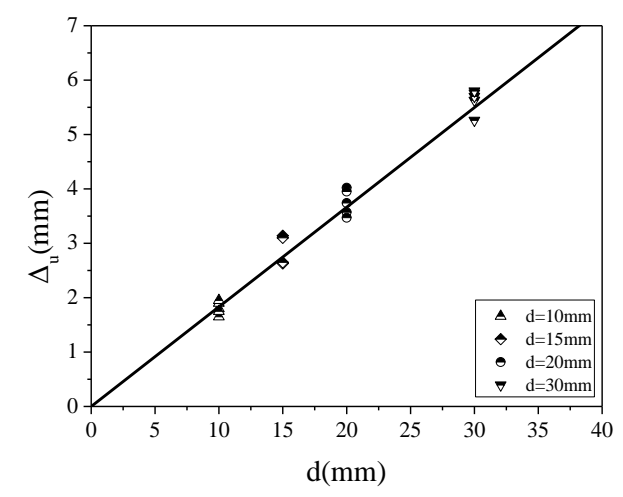

a

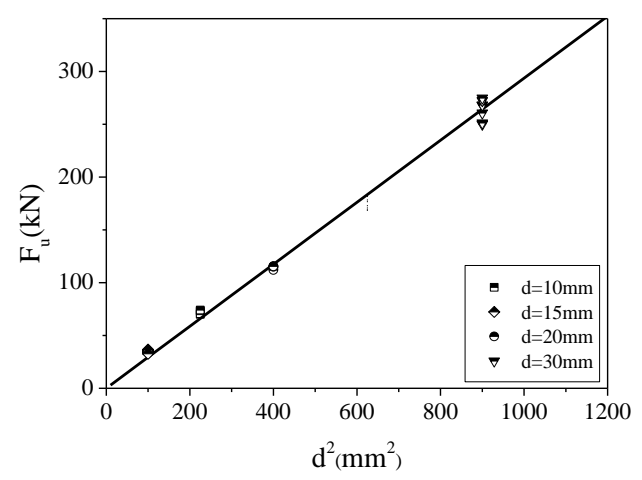

b

Fig. 7 Parameters of the linear model: a-the ultimate deformation; $b$ - the load capacity

\section{The bilinear model}

As shown in Fig. 6, the actual relation of dimensionless force to dimensionless shear deformation is nonlin- ear, so a bilinear model may describe the relation more accurately than the linear model. The bilinear model is characterized by the ultimate deformation $\Delta_{u}$, the load capacity $F_{u}$, the yield deformation $\Delta_{y}$, the yield force $F_{y}$, the initial stiffness $k_{1}$ and the post-yield stiffness $k_{2}$. Parameter definitions of the bilinear model are shown in Fig. 8.

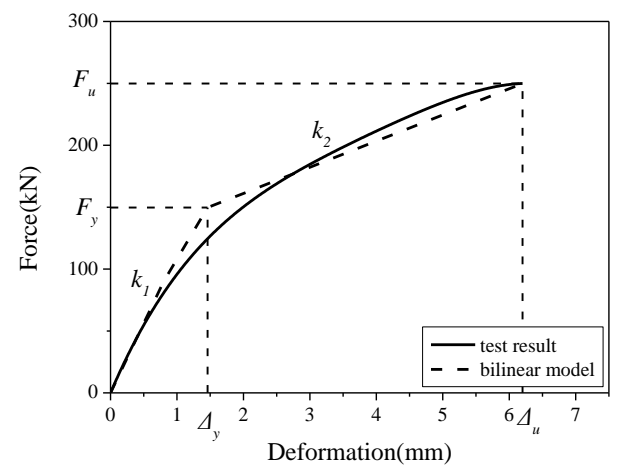

Fig. 8 Parameter definitions of the bilinear model
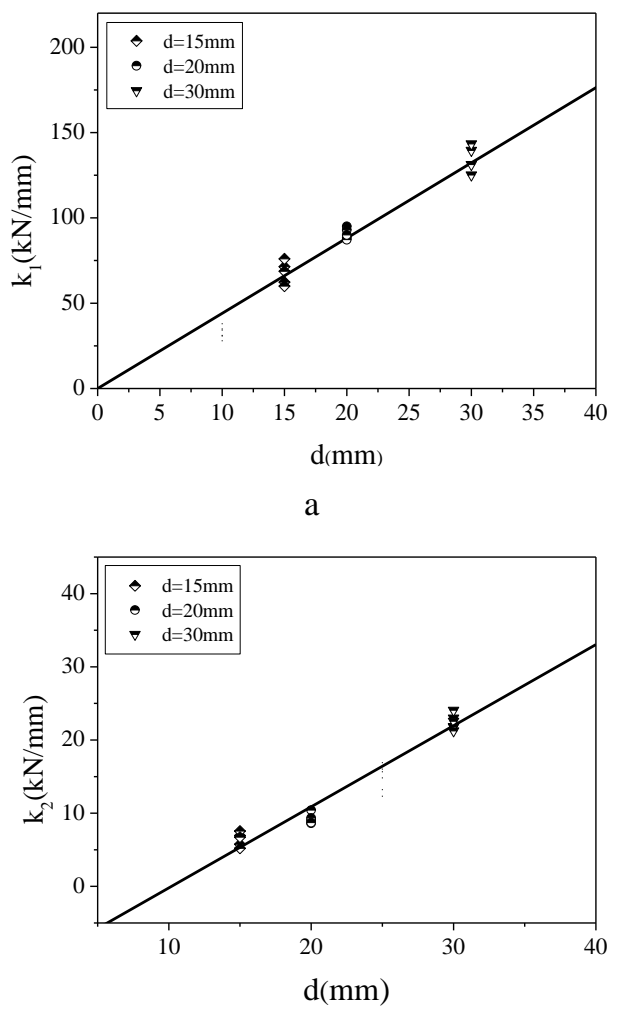

b

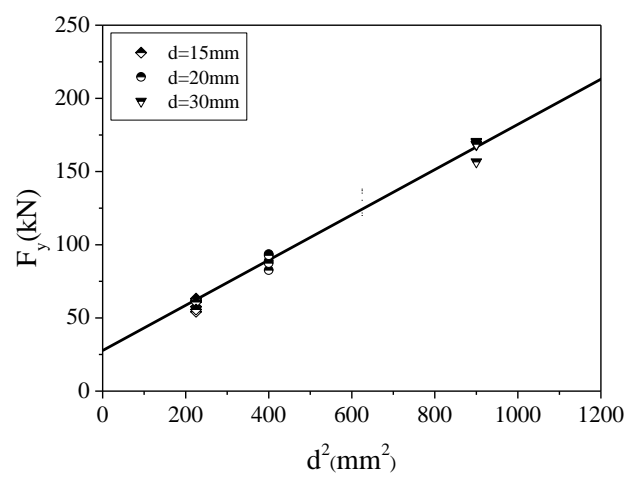

c

Fig. 9 Parameters of the bilinear model: a - the initial stiffness; $b$ - the post-yield stiffness; $c$ - the yield force 
$k_{1}$ of the bilinear model is determined by the initial slope of the test curve. $\Delta_{u}$ and $F_{u}$ can be determined by the maximum value of the test curve, which are the same as those of the linear model. The area under the test curve of shear deformation-force is a representative of energy dissipation. $\Delta_{y}, F_{y}$ and $k_{2}$ can be determined according to the principle that the area under the test curve is equal to that under the bilinear model curve. Relations of $k_{1}$ to $d, k_{2}$ to $d$ and $F_{y}$ to $d^{2}$ are shown in Fig. 9.

As shown, relations in Fig. 9 are almost linear. Empirical formulae for $k_{1}(\mathrm{kN} / \mathrm{mm}), k_{2}(\mathrm{kN} / \mathrm{mm}), F_{y}(\mathrm{kN})$ and $d$ $(\mathrm{mm})$ are fitted by the least square method and can be described as:

$$
\begin{aligned}
& k_{1}=4.4089 d \\
& k_{2}=1.1081 d-11.288 \\
& F_{\mathrm{y}}=0.1545 d^{2}+27.713 .
\end{aligned}
$$

\section{Comparisons of the two constitutive models}

In order to compare the two models of shear pins established above, a numerical analysis is conducted based on a two-span continuous girder bridge shown in Fig. 10, a. Each span is $30 \mathrm{~m}$, and the pier height is $20 \mathrm{~m}$. The material of the girder is C50 concrete, and that of the pier is C40 concrete. The cross section of the girder is shown in Fig. 10, b and that of the pier is a circle with a diameter of $4 \mathrm{~m}$. Two same double spherical seismic isolation bearings (DSSI bearing) are installed on the mid-pier, and the friction coefficients are 0.03 . Two same expansion bearings are installed on each of the two abutments. The working mechanism of the DSSI bearing in earthquakes is similar to a Friction Pendulum Sliding (FPS) bearing.

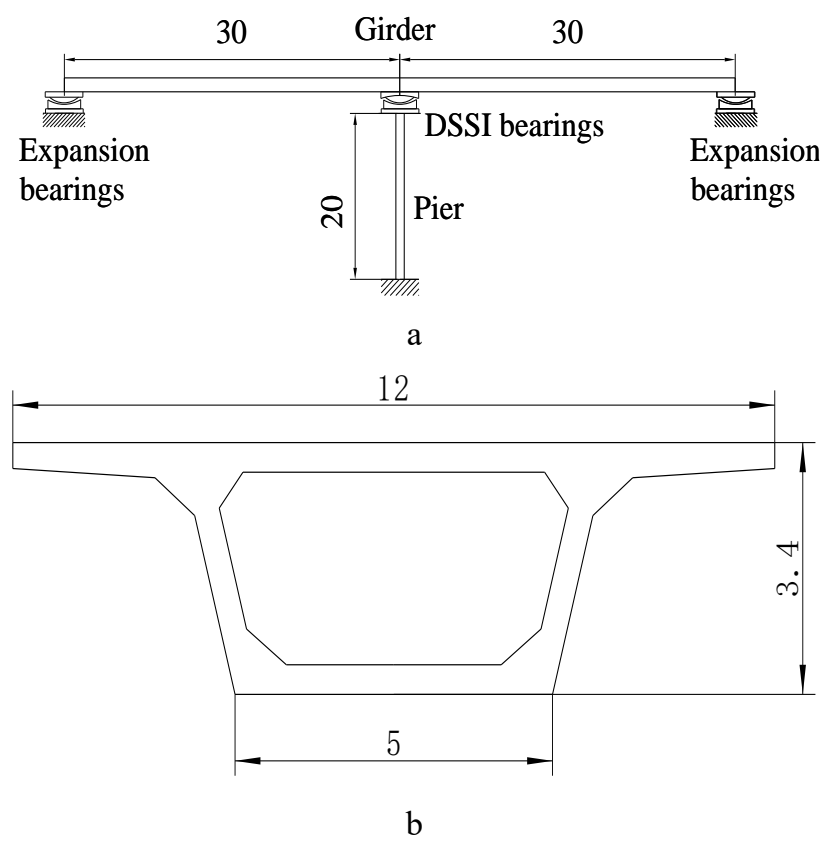

Fig. 10 The continuous girder bridge in the analysis (unit: $\mathrm{m}$ ): $\mathrm{a}$ - elevation view; $\mathrm{b}$ - cross section of the girder

The Beam 189 element of ANSYS is used to simulate the main girder, the cross beam and the pier. The element remains elastic in the analysis. Beam189 is based on Timoshenko beam theory and shear deformation effects are included. Combin40 spring element is used to simulate the bearings and shear pins. A complete Combin40 element has six parameters, including $\mathrm{K}_{1}, \mathrm{C}, \mathrm{M}$, GAP, FSLIDE and $\mathrm{K}_{2}$. For a DSSI bearing, $\mathrm{K}_{1}, \mathrm{~K}_{2}$ and FSLIDE are used. $\mathrm{K}_{1}$ is the Pre-sliding stiffness, $\mathrm{K}_{2}$ is the Post-sliding stiffness and FSLIDE is the maximum static friction force. For the linear model of shear pins, only $\mathrm{K}_{1}$ and FSLIDE are used. $\mathrm{K}_{1}$ is the equivalent shear stiffness and FSLIDE is the load capacity. For the bilinear model of shear pins, two Combin40 elements connected in series are used. The first one includes a $\mathrm{K}_{1}$ with a large value and an FSLIDE equal to the load capacity. The second one includes a $\mathrm{K}_{1}$ equal to the initial stiffness, a $\mathrm{K}_{2}$ equal to the post-yield stiffness and an FSLIDE equal to yield force.

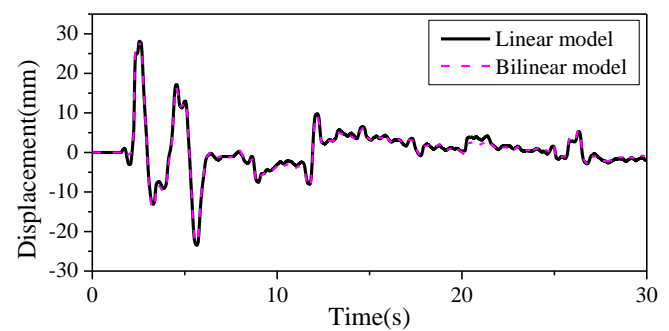

a

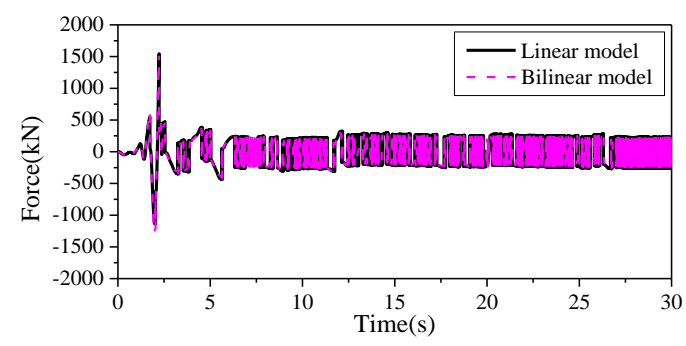

b

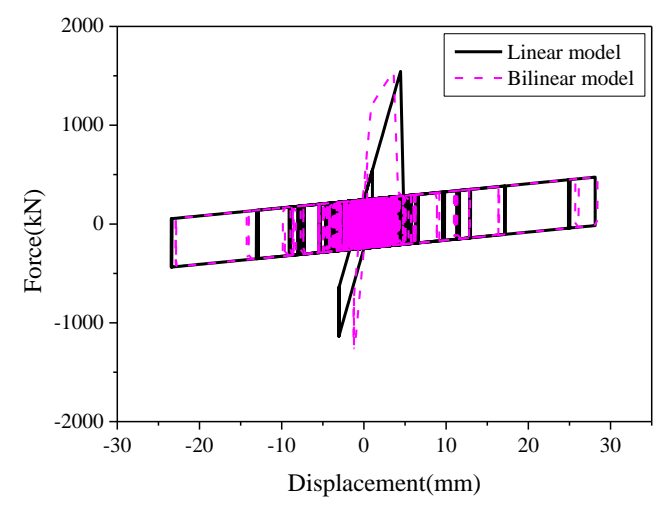

c

Fig. 11 Results of the DSSI bearing of EL-Centro seismic wave: a - displacement time histories; $b$ - force time histories; c - hysteretic curves

In the DSSI bearing, there are seven shear pins installed and the diameter of the central section of the shear pin is $25 \mathrm{~mm}$. The parameters of the shear pins are calculated by the linear and bilinear models established according to Eqs. (1)-(6). The EL-Centro and Kobe seismic waves with the peak ground acceleration of $0.1 \mathrm{~g}$ are selected in the finite element analysis. The analysis results of the two models are compared and shown in Figs. 11 and 12.

As shown, a little difference can be found between the hysteretic curves of the two models. However the displacement and force time histories of the two models are al- 
most the same. Therefore, although a bilinear model is more accurate, the linear model is simple, practical and can be chosen to simulate shear pin fractures acceptably in bridge seismic isolation design.

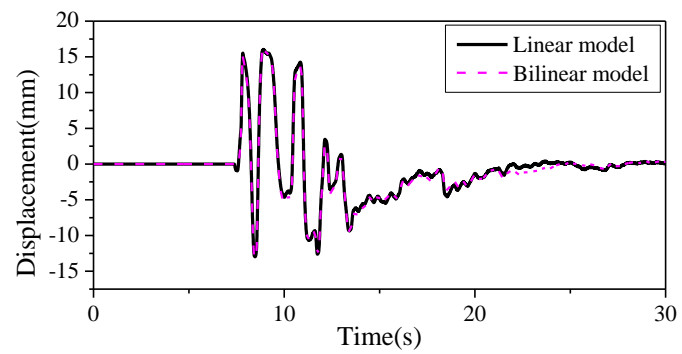

a

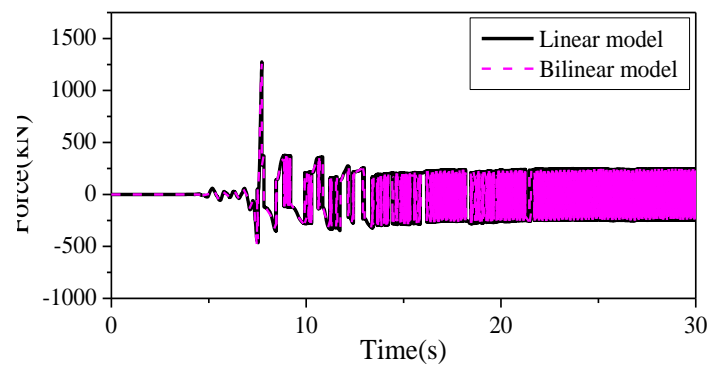

b

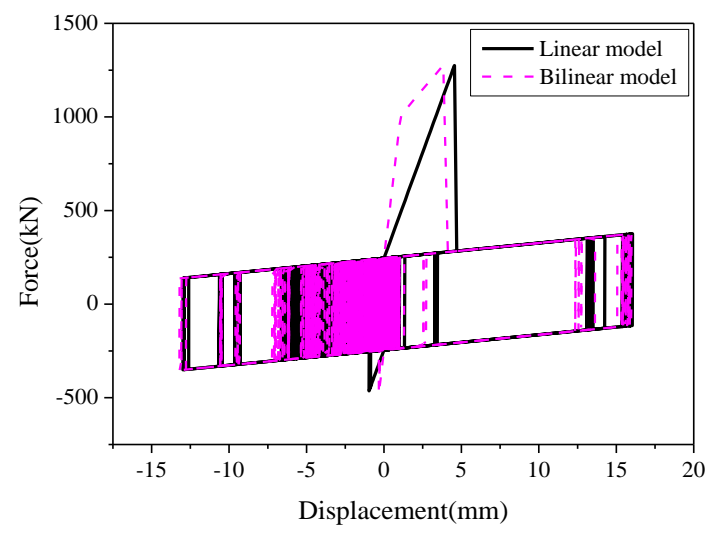

c

Fig. 12 Results of the DSSI bearing of Kobe seismic wave: a - displacement time histories; $b$ - force time histories; c - hysteretic curves

\section{Conclusions}

Shear fracture tests of shear pins were carried out firstly to establish the linear and bilinear constitutive models for shear pin fractures. Then the numerical analysis results with the two models were compared. The following conclusions were drawn:

1. Influences of the loading rate on the load capacity and ultimate deformation are negligible.

2. Ultimate deformation, equivalent stiffness, initial stiffness and post-yield stiffness are approximately proportional to the diameter of the shear pin. Yield force and load capacity are approximately proportional to the square of the diameter of the shear pin.

3. The linear model is simple, practical and accurate enough for the simulation of shear pin fractures in bridge seismic isolation design.

\section{Acknowledgments}

This work was supported in part by the National Natural Science Foundation of China (No. 51278372) and the Ministry of Science and Technology of China, Grant No. SLDRCE 14-B-15.

\section{References}

1. Zayas, V.; Low, S.; Mahin, S. 1987. The FPS earthquake resisting system, Technical Report UCB/EERC87/01, the University of California at Berkeley.

2. Zayas, V.; Low, S.; Bozzo, L.; Mahin, S. 1989. Feasibility and performance studies on improving the earthquake resistance of new and existing buildings using the friction pendulum system, Technical Report UBC/EERC-89/09, University of California at Berkeley.

3. Peng, T.B.; Li, J.Z.; Fan, L.C. 2008. Study on the seismic performance of a double spherical seismic isolation bearing, Earthquake Engineering and Engineering Vibration 7(4): 439-446. http://dx.doi.org/10.1007/s11803-008-1004-7.

4. Yuan, W.C.; Wang, B.B.; Cheung, P.C.; Cao, X.J.; Rong, Z.J. 2012. Seismic performance of cable-sliding friction bearing system for isolated bridges, Earthquake Engineering and Engineering Vibration 11(2): 173-183. http://dx.doi.org/10.1007/s11803-012-0108-2.

5. Filipov, E.T.; Revell, J.R. 2013. Seismic performance of highway bridges with fusing bearing components for quasi-isolation, Earthquake Engineering and Structural Dynamics 42(9): 1375-1394.

http://dx.doi.org/10.1002/eqe.2277.

6. Filipov, E.T.; Fahnestock, L. 2013. Evaluation of quasi-isolated seismic bridge behavior using nonlinear bearing models, Engineering Structures 49: 168-181. http://doi:10.1016/j.engstruct.2012.10.011.

7. Steelman, J.S.; Filipov, E.T. 2014. Experimental behavior of steel fixed bearings and implications for seismic bridge response, Journal of Bridge Engineering 19(8), A4014007. http://dx.doi.org/10.1061/(ASCE)BE.1943-5592.00005 40.

8. Rodgers J. E.; Mahin S. A. 2006. "Effects of connection fractures on global behavior of steel moment frames subjected to earthquakes," Journal of Structural Engineering, 132(1)78-88.

http://dx.doi.org/10.1061/(ASCE)0733-9445(2006)132: 1(78).

9. Xia, X.S.; Cheng, X.C.; Wang, X.H. 2012. Effect of the shear key on seismic response of the bridge using isolation bearing, Journal of Earthquake Engineering and Engineering Vibration 32(6): 104-109. 
Tianbo Peng, Ning Guo

EXPERIMENTAL AND NUMERICAL STUDIES OF SHEAR PIN FRACTURES BASED ON LINEAR AND BILINEAR MODELS

\section{S u m m ar y}

Shear pins are commonly used elements integrated with seismic isolation bearings to restrict the relative displacement between the superstructure and the substructure. However, constitutive models for seismic isolation bearings used in seismic isolation designs have not considered the effects of shear pin fractures. In order to establish the constitutive model of seismic isolation bearings with shear pin fractures considered, shear fracture tests of shear pins were conducted, and a linear model and a bilinear model for shear pin fractures were established. By comparing numerical results of different models, the linear constitutive model for shear pins was verified to be accurate enough and suggested to simulate the effects of shear pin fractures in seismic isolation designs.

Keywords: shear pin, shear fracture test, seismic isolation bearing, constitutive model.

Received November 06, 2015 Accepted July 04, 2016 